\title{
Conexões
}

Artigo Original

\section{Desempenho olímpico e paralímpico: uma análise comparativa entre países nosjogos Rio-2016}

Guilherme Moreira Caetano Pinto ${ }^{1}$ José Roberto Herrera Cantorani ${ }^{2}$ Bruno Pedroso ${ }^{3}$ Claudia Tania Picinin ${ }^{1}$ Luiz Alberto Pilatti ${ }^{1}$

\section{RESUMO}

O objetivo deste estudo é analisar de forma comparativa o desempenho olímpico e paralímpico dos países nos jogos Rio-2016. A referida análise é realizada com base em um quadro de medalhas unificado. Para tal, foi coletado o quadro de medalhas dos Jogos Olímpicos e Paralímpicos e, em sentido adicional, foi também considerado o tamanho populacional e o faturamento (Produto Interno Bruto) dos países que se constituem foco da presente análise. Verificou-se que China, Reino Unido e Estados Unidos apresentaram-se nas primeiras classificações em ambas as competições. Adicionalmente, encontrou-se que o faturamento e tamanho populacional são correlacionadas com o número total de medalhas e também com o número de medalhas de ouro. Conclui-se que o desempenho olímpico apresenta inter-relação com o faturamento e o tamanho populacional.

Palavras Chave: Olimpíadas. Paralimpíadas. Desempenho.

\footnotetext{
${ }^{1}$ Universidade Tecnológica Federal do Paraná

${ }^{2}$ Instituto Federal de São Paulo

${ }^{3}$ Universidade Federal de Ponta Grossa

Submetido em: 25 jan. 2017

Aceito em: 02 jun. 2017

Contato: prof.brunopedroso@gmail.com

Conexões: Educ. Fís., Esporte e Saúde, Campinas: SP, v. 15, n. 3, p. 319-337, jul./set. 2017. ISSN: 1980-9030
} 


\section{Olimpic and paralympic performance: $a$ comparative analysis between countries in Rio-2016}

\section{Abstract}

The objective of this study is to conduct a comparative analysis of the Olympic and Paralympic performance of some countries in the Olympic Games Rio-2016. This analysis was based on a unified medal table. In order to do so, we collected the medal table table of the Olympic and Paralympic Games and also took into account additional data, such as population size and gross domestic product of the countries in question. We found that China, the United Kingdom and the United States conquered the first places in both competitions. Additionally, we found a correlation between the total amount of medals and to the amount of gold medals and gross domestic product and population size. We concluded that the Olympic performance is interrelated to gross domestic product and the population size.

Keywords: Olympics. Paralympics. Performance

\section{Rendimiento olímpico y paralímpico: un análisis comparativo entre países en los juegos Río-2016}

\section{RESUMEN}

El objetivo de este estudio es analizar comparativamente el rendimiento olímpico y paralímpico de los países en Rio 2016. El análisis se realiza basada en medallero unficiado. Para este enálisis consultamos el medalleros de los Juegos Olímpicos y Paralímpicos y también consideramos el tamaño de la población y el producto interno bruto de los países en cuestión en este análisis. Se encontró que China, Reino Unido y Estados Unidos se presentaron en las primeras calificaciones en ambas competiciones. Además, se encontró que el tamaño del producto interno bruto y de la población se correlacionan con la cantidad total de las medallas y con la cantidad de medallas de oro. Se concluye que el rendimiento olímpico se correlaciona con el producto interno bruto y el tamaño de la población.

Palabras Clave: Juegos olímpicos. Juegos paralímpicos. Rendimiento. 


\section{INTRODUÇÃO}

Os Jogos Olímpicos da era moderna tiveram início em 1896, na cidade grega de Atenas. O primeiro e o segundo colocados recebiam, respectivamente, uma medalha de prata e uma medalha de bronze (COLLI, 2004).

Nos Jogos de St Louis-1904 (Estados Unidos) a forma de premiação foi alterada para aquela que segue até os dias atuais: o primeiro colocado de cada modalidade/prova/categoria recebe uma medalha de ouro, o segundo colocado recebe uma medalha de prata e, por fim, o terceiro colocado recebe uma medalha de bronze (COLLI, 2004). Desde então, tornou-se comum registrar os resultados dos Jogos Olímpicos em todo o mundo, seja por parte dos profissionais ou dos espectadores, como forma de eternizar os momentos marcantes (ARAÚJO, 2013).

Novas modalidades esportivas passaram a fazer parte dos Jogos Olímpicos da era moderna desde a sua primeira edição. A edição Rio-2016 dos Jogos Olímpicos foi composta por 41 modalidades: Tiro com arco, Atletismo, Badminton, Basquete, Vôlei de praia, Boxe, Canoagem Slalom, Canoagem Sprint, Ciclismo BMX, Ciclismo Mountain Bike, Ciclismo de estrada, Ciclismo de pista, Saltos ornamentais, Hipismo adestramento, Hipismo salto, Hipismo evento, Esgrima, Futebol, Golfe, Ginástica Artística, Ginástica Rítmica, Handebol, Hóquei, Judô, Pentatlo moderno, Remo, Rugby, Vela, Tiro esportivo, Natação, Nado sincronizado, Tênis de mesa, Taekwondo, Tênis, Trampolim, Triatlo, Voleibol, Polo Aquático, Levantamento de peso, luta olímpica, Luta greco-romana (COMITÊ OLÍMPICO INTERANCIONAL, 2016). Em razão da existência de modalidades para o gênero masculino e o feminino, e de diferentes provas e/ou categorias para determinadas modalidades, o total de medalhas distribuídas na edição Rio-2016 foi de 307 de ouro, 307 de prata e 360 de bronze. O número mais elevado de medalhas de bronze se deve ao fato de que, em algumas modalidades de lutas, dois atletas são premiados com a medalha de bronze, ao invés de apenas um.

Em relação às Paralimpíadas cabe mencionar inicialmente a origem do esporte adaptado, que ocorreu na Inglaterra, na cidade de Aylesbury, por intermédio do neurologista Ludwig Guttmann. Este, a fim de atender a uma solicitação do governo britânico, concebeu o Centro Nacional de Lesionados Medulares do Hospital de Stoke Mandeville, cujo propósito era melhorar a vida de indivíduos que haviam se lesionado na Segunda Guerra Mundial (COSTA; SOUSA, 2004).

O esporte adaptado tornou-se oficial em 1948, com a realização dos Jogos de Stoke Mandeville. Sua internacionalização ocorreu em 1952, quando foram realizados os Jogos Internacionais de Stoke Mandeville, disputado pelo Centro Militar de Reabilitação de Doorn (Países Baixos) e os britânicos de Stoke Mandeville. Seguindo 
um sentido histórico progressivo, após a recém mencionada evolução e internacionalização do esporte adaptado, em Roma, no ano de 1960, foram disputados os primeiros Jogos Paralímpicos, incialmente nominados de Olimpíadas dos Portadores de Deficiência (COSTA; SOUSA, 2004).

Cabe ressaltar que o esporte adaptado faz uso de um sistema de classificação funcional, cuja gênese se justifica a partir da necessidade de que todos os atletas participem da competição em condição de igualdade, almejando resultados mais justos. Destaca-se ainda que, a classificação funcional, para cumprir seu objetivo, ocorre por meio de classes que representam o grau de comprometimento funcional dos atletas para cada modalidade (MARQUES et al., 2009).

A edição Rio-2016 das Paralimpíadas foi composta pelas seguintes modalidades: Atletismo, Basquete em cadeira de rodas, Bocha, Canoagem, Ciclismo, Esgrima de cadeira de rodas, Futebol de 5, Futebol de 7, Golbol, Halterofilismo, Hipismo, Judô, Natação, Remo, Rugby em cadeira de rodas, Tênis de mesa, Tênis em cadeira de rodas, Tiro com arco, Tiro esportivo, Triatlo, Vela e Voleibol sentado (INTERNATIONAL PARALYMPIC COMMITTEE, 2016).

A premiação nos Jogos Paralímpicos segue o mesmo modelo da realizada nos Jogos Olímpicos a partir da edição de St Louis-1904. Respeitando a existência de modalidades para o gênero masculino e o feminino e, as diferentes provas e/ou categorias por classificação funcional, o total de medalhas distribuídas na edição Rio2016 foi de 529 de ouro, 529 de prata e 539 de bronze (INTERNATIONAL PARALYMPIC COMMITTEE, 2016). Ressalta-se novamente que o número maior de medalhas de bronze ocorre em virtude das modalidades em que há distribuição de duas medalhas de bronze, ao invés de apenas uma.

A premiação, nos Jogos Olímpicos e Paralímpicos, é utilizada para destacar os atletas com o melhor desempenho. Entretanto, o mesmo não se replica quanto a uma classificação olímpica por países. Segundo o Conselho Federal de Educação Física (CONSELHO FEDERAL DE EDUCAÇÃO FÍSICA, 2012), na carta olímpica documento que regulamenta os Jogos Olímpicos - não há menção a qualquer classificação nos Jogos Olímpicos por meio do desempenho geral das nações que têm atletas em competição. Além disso o Comitê Olímpico Internacional (COI) não divulga nenhuma classificação olímpica por nações em seu site oficial.

Em que pese o cenário acima exposto, a mídia divulga um quadro de medalhas para classificar os países em relação à performance de seus atletas, que considera como critério para classificação o número de medalhas de ouro. Caso haja um empate, considera-se as medalhas de prata e, persistindo o empate, considera-se as medalhas de bronze. 
Contrariamente ao que inúmeros expectadores acreditam, o quadro de medalhas disponibilizado pela mídia não é oficial. Este foi criado pela mídia dos Estados Unidos para valorizar as vitórias esportivas do país, atendendo a um propósito político. Ressalta-se ainda que, nos jogos de Pequim-2008 (China), os Estados Unidos divulgaram um quadro de medalhas que considerava como critério de classificação o número total de medalhas, visto que haviam conquistado menos medalhas de ouro do que a China e, considerando o número total de medalhas, ocupariam a primeira colocação (CONSELHO FEDERAL DE EDUCAÇÃO FÍSICA, 2012).

Diferentemente do COI, no site do Comitê Paralímpico Internacional é disponibilizado um quadro de medalhas, que segue os critérios expostos pelo quadro de medalhas dos Jogos Olímpicos disponibilizado pela mídia, tal qual pode ser verificado na figura 1:
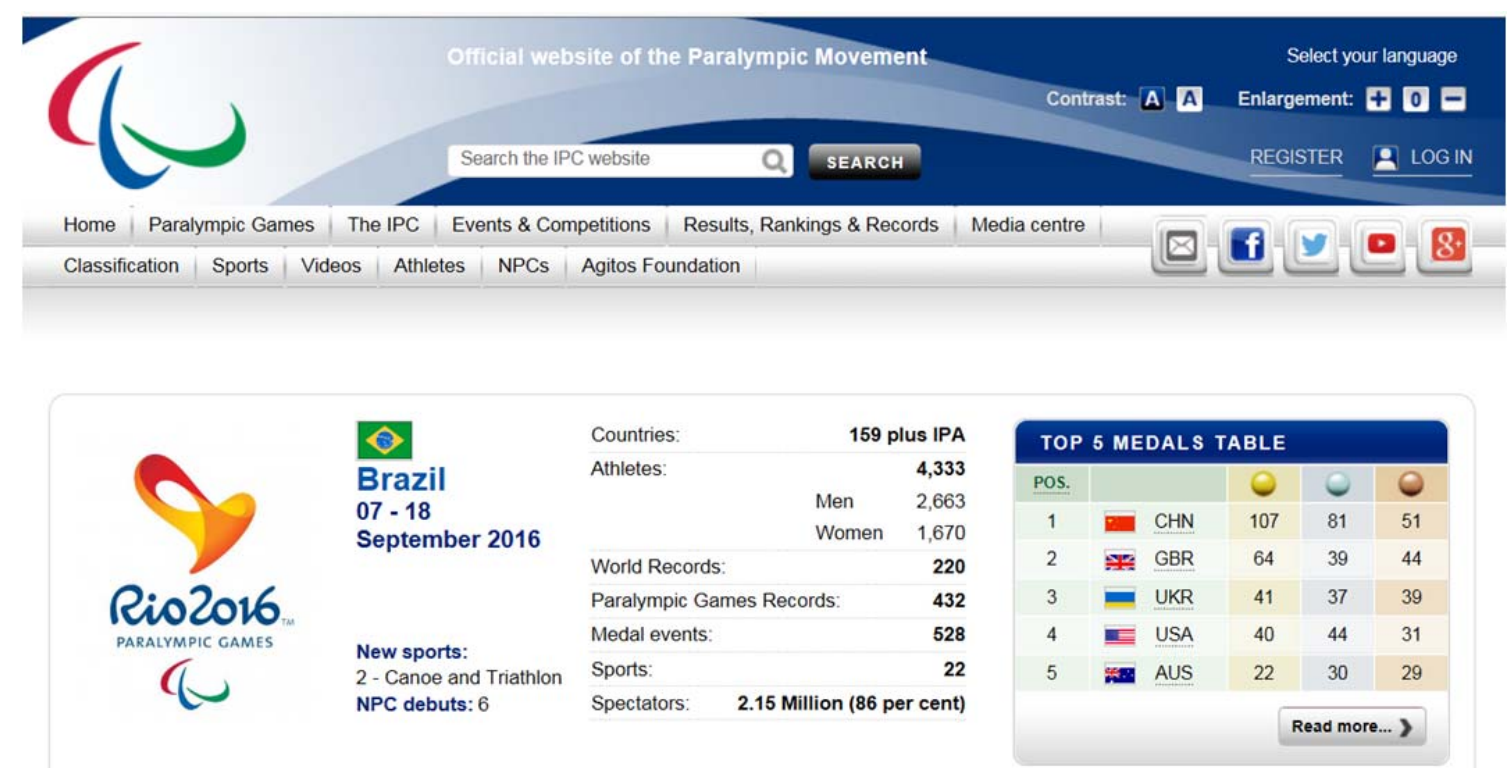

Figura 1 - Quadro de medalhas disponível no site do Comitê Paralímpico Internacional Fonte: International Paralympic Committee (2016).

Ciente das controvérsias quanto à adoção ou não do quadro de medalhas nos Jogos Olímpicos e Paralímpicos e, mesmo que propor uma classificação olímpica/paraolímpica não seja a intenção do presente estudo, os autores entendem que uma análise do desempenho olímpico e paralímpico dos países, de forma conjunta, torna-se interessante, ao passo que permite demonstrar algumas situações que não são possíveis de se constatar a partir da análise do desempenho isoladamente nos Jogos Olímpicos ou Paralímpicos.

Com base na premissa supracitada, o objetivo do presente estudo é analisar, de forma comparativa, o desempenho olímpico e paralímpico dos países nos jogos Rio2016 por meio de um quadro de medalhas unificado, construído a partir do quadro de medalhas disponibilizado pela mídia. 


\section{Procedimentos Metodológicos}

O presente estudo é de natureza aplicada, com delineamento quantitativo em relação à abordagem do problema, exploratório quanto aos objetivos, e documental quanto aos seus procedimentos.

A coleta de dados referentes aos números de medalhas dos Jogos Olímpicos e Paralímpicos da edição Rio-2016 foi realizada a partir dos dados veiculados pela mídia, que invariavelmente têm sido os mesmos nos diferentes meios de comunicação.

Para a classificação unificada dos países em relação ao desempenho olímpico e paralímpico utilizou-se duas formas. Em um primeiro momento, a classificação ocorreu por meio da soma do número total de medalhas, aqui nominada de "Quadro de classificação olímpica-paralímpica pela soma do total de medalhas". Nesta classificação, foram somados o número total de medalhas obtidas nos Jogos Olímpicos com o número total de medalhas obtidas nos Jogos Paralímpicos. Para ranquear os países, seguiu-se o método utilizado pelo quadro de medalhas utilizado pela mídia, que considera primeiramente o número de medalhas de ouro, seguido das medalhas de prata e bronze, como já descrito anteriormente.

Em um segundo momento, tendo em vista que as Olimpíadas e Paralimpíadas apresentam um número de medalhas distintos, resultado das diferentes modalidades e/ou provas/categorias disputadas nestas competições, foi elaborada uma classificação considerando um fator de correção, de forma a equiparar o número de medalhas conquistadas nos Jogos Olímpicos em relação aos Jogos Paralímpicos. Este fator foi calculado por meio da multiplicação do número de medalhas de ouro e de medalhas de prata por 1,72549 e do número de medalhas de bronze por 1,50696.

O fator de correção de equidade foi alcançado a partir da razão entre o número de medalhas de ouro, prata e bronze em disputa na Paralimpíada e na Olimpíada. Dessa forma, o total de medalhas de ouro em disputa na Paralimpíada (528), dividido pelo total de medalhas de ouro em disputa na Olimpíada (306), resultou em um fator de correção de 1,72549. Da mesma forma, o total de medalhas de prata em disputa na Paralimpíada (528), dividido pelo total de medalhas de prata em disputa na Olimpíada (306), resultou em um fator de correção de 1,72549. E, de igual maneira, o total de medalhas de bronze em disputa na Paralimpíada (541), dividido pelo total de medalhas de bronze em disputa na Olimpíada (359), resultou em um fator de correção de 1,50696.

Cabe ressaltar que a divergência entre o número de medalhas em disputa - aqui utilizado para o cálculo do fator de correção - e o número de medalhas distribuídas retratado anteriormente no presente estudo - se deve ao fato da ocorrência de empates. O empate é previsto em ambas as competições e segue os seguintes critérios: nos casos 
em que há empate entre dois competidores na primeira colocação, ambos são premiados com medalha de ouro e não há distribuição de medalha de prata; quando o empate ocorre entre dois competidores na segunda colocação, ambos são premiados com medalha de prata e não há distribuição de medalha de bronze; por fim, quando o empate entre dois competidores ocorre na terceira colocação, ambos são premiados com medalha de bronze, havendo portanto a distribuição de uma medalha de bronze adicional. A mesma lógica é seguida nos casos em que há empate entre três ou mais competidores nas colocações que preveem distribuição de medalhas.

O número de habitantes das nações que obtiveram medalhas nos Jogos Olímpicos e Paralímpicos Rio-2016 foram obtidos por meio dos sites dos órgãos governamentais pelo recenseamento da população de cada país. Quanto às nações de Cabo Verde, Costa do Marfim, Grécia, Paquistão, Romênia e Kuwait, em que a atualização dos dados em seus sites governamentais ocorreu em um período anterior a 01 de julho de 2015, os dados foram coletados através da última atualização do World Population Prospects (ORGANIZAÇÃO DAS NAÇÕES UNIDAS, 2016), publicado pela Organização das Nações Unidas (ONU) na data de 01 de julho de 2016.

Tendo em vista que muitas nações não disponibilizam o número de imigrantes estrangeiros vivendo em cada país e, também, o número de indivíduos nascidos em seu país que vivem em outras nações, considerou-se como dado populacional o número de habitantes que reside em cada país.

No que se refere ao Produto Interno Bruto (PIB), os dados foram obtidos por meio de consulta à lista divulgada pelo portal do Banco Mundial (THE WORLD BANK, 2016) dos PIBs nominais dos países em 2015. Nos casos de Cuba e Taiwan, que não se encontravam na lista, utilizou-se os valores disponibilizados pela ONU (ORGANIZAÇÃO DAS NAÇÕES UNIDAS, 2016) e pelo Fundo Monetário Internacional (INTERNATIONAL MONETARY FUND, 2016), respectivamente.

De posse dos dados coletados, foi efetuado o teste de normalidade dos dados de Kolmogorov-Smirnov e a correlação de Spearman entre as variáveis PIB, tamanho populacional, número de medalhas de ouro e número total de medalhas. O teste de correlação de Spearman foi escolhido por não haver linearidade dos dados analisados. Ou seja, tanto no caso das Olimpíadas quanto das Paralimpíadas, os dados foram considerados não normais $(\mathrm{p}<0,05)$. Os cálculos estatísticos foram efetuados por meio do software Statistical Package for the Social Sciences (SPSS) para Windows, versão 23.0.

Nos cálculos de correlação de Spearman que envolveram o número de medalhas do ouro, foram considerados todos os países que conquistaram ao menos uma medalha de ouro, sendo estes 59 nas Olimpíadas e 63 nas Paralimpíadas. Já nos que envolveram 
o número total de medalhas, considerou-se todos os países que conquistaram medalhas, sendo estes 87 nas Olimpíadas e 83 nas Paralimpíadas.

Para as análises, foram utilizados os critérios propostos por Dancey e Reidy (2006), para constatar a força das correlações, no qual: $\rho=0,10$ a 0,30 representa correlação fraca; $\rho=0,40$ a 0,60 representa correlação; $\rho=0,70$ a 0,9 representa correlação e $\rho=1,00$ correlação perfeita, tanto para valores negativos quanto para valores positivos. Para análise dos resultados foi considerado nível de significância de $95 \%$.

\section{Resultados Discussão}

O Quadro 1 apresenta o quadro de medalhas veiculado pela mídia na Olimpíada e na Paralimpíada da edição dos jogos Rio-2016, com o número de medalhas que cada país conquistou em ambas as competições e suas respectivas classificações, além da soma bruta do número total de medalhas:

Quadro 1 - Quadro de medalhas veiculado pela mídia na Olimpíada e Paralimpíada Rio-2016 e soma bruta do número de medalhas em ambas as competições e suas respectivas classificações

\begin{tabular}{|c|c|c|c|c|c|c|c|c|c|c|c|c|c|c|c|}
\hline \multirow{2}{*}{$\begin{array}{l}\text { COLOCACAO } \\
\text { PELA SOMA } \\
\text { BRUTA }\end{array}$} & \multirow{2}{*}{$\begin{array}{c}\text { COLOCACAAO } \\
\text { (OLIMP.) }\end{array}$} & \multirow{2}{*}{$\begin{array}{l}\text { COLOCACACAO } \\
\text { (PARALIMP.) }\end{array}$} & \multirow{2}{*}{ PAls } & \multicolumn{4}{|c|}{ OLIMPIADAS } & \multicolumn{4}{|c|}{ PARALIMPIADAS } & \multicolumn{4}{|c|}{ SOMA BRUTA } \\
\hline & & & & OURO & PRATA & BRONZE & TOTAL & OURO & PRATA & BRONZE & TOTAL & OURO & PRATA & BRONZE & TOTAL \\
\hline $01^{\circ}$ & $03^{\circ}$ & $01^{\circ}$ & China & 26 & 18 & 26 & 70 & 107 & 81 & 51 & 239 & 133 & 99 & 77 & 309 \\
\hline $02^{\circ}$ & $01^{\circ}$ & $04^{\circ}$ & $\begin{array}{l}\text { Estados } \\
\text { Unidos }\end{array}$ & 46 & 37 & 38 & 121 & 40 & 44 & 31 & 115 & 86 & 81 & 69 & 236 \\
\hline $03^{\circ}$ & $02^{\circ}$ & $02^{\circ}$ & Reino Unido & 27 & 23 & 17 & 67 & 64 & 39 & 44 & 147 & 91 & 62 & 61 & 214 \\
\hline $04^{\circ}$ & $31^{\circ}$ & $03^{\circ}$ & Ucrània & 2 & 5 & 4 & 11 & 41 & 37 & 39 & 117 & 43 & 42 & 43 & 128 \\
\hline $05^{\circ}$ & $10^{\circ}$ & $05^{\circ}$ & Australia & 8 & 11 & 10 & 29 & 22 & 30 & 29 & 81 & 30 & 41 & 39 & 110 \\
\hline $06^{\circ}$ & $05^{\circ}$ & $06^{\circ}$ & Alemanha & 17 & 10 & 15 & 42 & 18 & 25 & 14 & 57 & 35 & 35 & 29 & 99 \\
\hline $07^{\circ}$ & $13^{\circ}$ & $08^{\circ}$ & Brasil & 7 & 6 & 6 & 19 & 14 & 29 & 29 & 72 & 21 & 35 & 35 & 91 \\
\hline $08^{\circ}$ & $07^{\circ}$ & $12^{\circ}$ & França & 10 & 18 & 14 & 42 & 9 & 5 & 14 & 28 & 19 & 23 & 28 & 70 \\
\hline $09^{\circ}$ & $11^{\circ}$ & $07^{\circ}$ & Holanda & 8 & 7 & 4 & 19 & 17 & 19 & 26 & 62 & 25 & 26 & 30 & 81 \\
\hline $10^{\circ}$ & $04^{\circ}$ & - & Rússia & 19 & 18 & 19 & 56 & & & & & 19 & 18 & 19 & 56 \\
\hline $11^{\circ}$ & $06^{\circ}$ & $64^{\circ}$ & Japâo & 12 & 8 & 21 & 41 & & 10 & 14 & 24 & 12 & 18 & 35 & 65 \\
\hline $12^{\circ}$ & $09^{\circ}$ & $09^{\circ}$ & |tália & 8 & 12 & 8 & 28 & 10 & 14 & 15 & 39 & 18 & 26 & 23 & 67 \\
\hline $13^{\circ}$ & $08^{\circ}$ & $20^{\circ}$ & Coreia do Sul & 9 & 3 & 9 & 21 & 7 & 11 & 17 & 35 & 16 & 14 & 26 & 56 \\
\hline $16^{\circ}$ & $33^{\circ}$ & $10^{\circ}$ & Polónia & 2 & 3 & 6 & 11 & 9 & 18 & 12 & 39 & 11 & 21 & 18 & 50 \\
\hline $25^{\circ}$ & $23^{\circ}$ & $37^{\circ}$ & Colômbia & 3 & 2 & 3 & 8 & 2 & 5 & 10 & 17 & 5 & 7 & 13 & 25 \\
\hline $50^{\circ}$ & $27^{\circ}$ & $54^{\circ}$ & Argentina & 3 & 1 & & 4 & 1 & 1 & 3 & 5 & 4 & 2 & 3 & 9 \\
\hline $52^{\circ}$ & $65^{\circ}$ & $65^{\circ}$ & Venezuela & & 1 & 2 & 3 & & 3 & 3 & 6 & 0 & 4 & 5 & 9 \\
\hline $92^{\circ}$ & $\cdot$ & $76^{\circ}$ & $\begin{array}{c}\cdot \\
\end{array}$ & & & & & & & 1 & 1 & 0 & 0 & 1 & 1 \\
\hline
\end{tabular}

Nota: **Empate entre sete países: Arábia Saudita, Bósnia-Herzegovina, Cabo Verde, Moçambique, Paquistão, Sri Lanka e Uganda.

Verifica-se que a China (133 ouros, 99 pratas, 77 bronzes) é o país que apresentou a maior soma bruta de medalhas olímpicas e paralímpicas, seguida de Estados Unidos ( 86 ouros, 81 pratas, 69 bronzes), Reino Unido (91 ouros, 62 pratas, 61 bronzes), Ucrânia (43 ouros, 42 pratas, 43 bronzes) e Austrália (30 ouros, 41 pratas, 39 bronzes. 
Não obstante, nota-se que China $\left(3^{\circ}\right.$ e $\left.1^{\circ}\right)$, Estados Unidos $\left(1^{\circ}\right.$ e $\left.4^{\circ}\right)$, Reino Unido $\left(2^{\circ}\right.$ e $\left.2^{\circ}\right)$, Austrália $\left(10^{\circ}\right.$ e $\left.5^{\circ}\right)$, Alemanha $\left(5^{\circ}\right.$ e $\left.6^{\circ}\right)$, e Itália $\left(9^{\circ}\right.$ e $\left.9^{\circ}\right)$ permaneceram nas dez primeiras colocações nas Olimpíadas e Paralimpíadas. Cabe mencionar que a Rússia ficou em décimo lugar na classificação pela soma bruta de medalhas, mesmo com o seu banimento da Paralimpíada em virtude de questões relacionadas ao doping.

O cenário acima exposto, com a exceção do caso da Rússia, evidencia que a China, os Estados Unidos, o Reino Unido, a Austrália, a Alemanha e a Itália se configuram como potências olímpicas e paralímpicas, com desempenho elevado em ambas as competições.

Neste sentido, Austrália, China e o Reino Unido realizam um planejamento olímpico direcionado aos atletas e às condições que influenciam o seu desempenho olímpico, a fim de que o país obtenha uma vantagem competitiva. Além disso, Santos, Costa e Silva (2012) baseiam-se em diversos autores para afirmar que o potencial econômico (PIB) e o tamanho populacional contribuem para o sucesso esportivo de uma nação.

Tal perspectiva é reforçada pela análise do PIB e do tamanho populacional da China (PIB: 10866444/População: 1378820000), Estados Unidos (PIB: 17946996/População: 324507000), Reino Unido (PIB: 2848755/População: 65110000), Austrália (PIB: 1339539/População: 24191700), Alemanha (PIB: 3355772/População: 81770900) e Itália (PIB: 1814763/População: 60665551).

Observa-se que a China é o país mais populoso do mundo, e tem um PIB bastante elevado. Estados Unidos, Reino Unido, Austrália, Alemanha e Itália também apresentam valores elevados nas duas variáveis.

Entende-se como pertinente, considerando as variáveis PIB e tamanho populacional, efetuar o cálculo de correlação destas pelo número de medalhas no contexto olímpico e paralímpico. Em relação às variáveis referentes às Olimpíadas, obtiveram-se dados não normais com $\mathrm{p} \leq 0,05$ (número de ouro - Kolmogorov-Smirnov, $\mathrm{p} \leq 0,001$; número total de medalhas - Kolmogorov-Smirnov, $\mathrm{p} \leq 0,001$; PIB Kolmogorov-Smirnov, $\mathrm{p} \leq 0,001$; tamanho populacional - Kolmogorov-Smirnov, $\mathrm{p} \leq 0,001$ ). Diante do exposto, optou-se pelo cálculo de correlação de Spearman (teste não paramétrico) entre às variáveis (i) número de ouro, (ii) total de medalhas, (iii) PIB, (iv) tamanho populacional. Os resultados retornados para o coeficiente de correlação, probabilidade associada (p-valor) e número de casos válidos $(\mathrm{N})$ estão descritos na Tabela 1: 
Tabela 1 - Correlação de Spearman entre as variáveis olímpicas de número de ouro, total de medalhas, PIB e população

\begin{tabular}{|c|c|c|c|c|c|c|}
\hline \multicolumn{7}{|c|}{ Correlações } \\
\hline & & & Ouro & $\begin{array}{l}\text { Total de } \\
\text { medalhas }\end{array}$ & PIB & POPULAÇÃO \\
\hline \multirow[t]{12}{*}{$\begin{array}{l}\text { rô de } \\
\text { Spearman }\end{array}$} & \multirow[t]{3}{*}{ Ouro } & $\begin{array}{l}\text { Coeficiente de } \\
\text { Correlação }\end{array}$ & 1,000 & $0,844^{* *}$ & $0,633^{* *}$ & \\
\hline & & Sig. (bilateral) & & 0,001 & 0,001 & 0,001 \\
\hline & & $\mathrm{N}$ & 59 & 59 & 59 & 59 \\
\hline & \multirow[t]{3}{*}{$\begin{array}{l}\text { Total de } \\
\text { medalhas }\end{array}$} & $\begin{array}{l}\text { Coeficiente de } \\
\text { Correlação }\end{array}$ & & 1,000 & $0,528^{* *}$ & $0,451^{* *}$ \\
\hline & & Sig. (bilateral) & 0,001 & & 0,001 & 0,001 \\
\hline & & $\mathrm{N}$ & 59 & 87 & 87 & 87 \\
\hline & \multirow[t]{3}{*}{ PIB } & $\begin{array}{l}\text { Coeficiente de } \\
\text { Correlação }\end{array}$ & $0,633^{* *}$ & $0,528^{* *}$ & 1,000 & $0,695^{* *}$ \\
\hline & & Sig. (bilateral) & 0,001 & 0,001 & & 0,001 \\
\hline & & $\mathrm{N}$ & 59 & 87 & 98 & 98 \\
\hline & \multirow[t]{3}{*}{ POPULAÇÃO } & $\begin{array}{l}\text { Coeficiente de } \\
\text { Correlação }\end{array}$ & $0,487^{* *}$ & $0,451^{* *}$ & $0,695^{* *}$ & 1,000 \\
\hline & & Sig. (bilateral) & 0,001 & 0,001 & 0,001 & \\
\hline & & $\mathrm{N}$ & 59 & 87 & 98 & 98 \\
\hline
\end{tabular}

Nota: ** A correlação é significativa no nível 0,001 (bilateral).

Para $\mathrm{p}$-valor $=0,000$ utilizou-se arredondamento para $\mathrm{p}$-valor $=0,001$, seguindo recomendações.

Fonte: propostas na obra de DANCEY; REIDY (2006).

Destaca-se que todas às correlações retornadas são significativas com $\mathrm{p} \leq 0,001, \mathrm{o}$ que indica que há $99 \%$ de chance dos dados investigados estarem corretos. A classificação dos valores retornados pelo cálculo de correlação de Spearman $(\rho)$, alicerçadas na literatura de Dancey e Reidy (2006), aponta que há uma forte correlação entre às variáveis Total de Medalhas e número de ouro $(\rho=0,844)$, e uma correlação moderada entre às variáveis PIB e número de ouro $(\rho=0,633)$ e PIB e total de medalhas $(\rho=0,528)$. Ademais, ressalta-se que as correlações retornadas se apresentaram positivas, o que, de acordo com Dancey e Reidy (2006), indica que valores altos de uma primeira variável tendem a estar relacionados com valores altos de uma segunda variável.

Alicerçado neste pressuposto, infere-se que, na medida em que o número total de medalhas de um país se eleva, o número de medalhas de ouros também tende a aumentar. Sendo assim, a tendência é que os países que tenham um elevado número total de medalhas, também conquistem um elevado número de medalhas de ouro. Aventa-se então que, um país com bom desempenho olímpico, consegue disputar medalhas em diversas modalidades, aumentando a possibilidade de conquistar um elevado número total de medalhas e, por conseguinte, ampliando a probabilidade de elevar seu número de medalhas de ouro.

Não obstante, ainda que de forma moderada, observa-se que, na medida em que o PIB aumenta o número de medalhas de ouro, e o número total de medalhas conquistadas também se eleva. Em outras palavras, os cálculos acima expostos 
evidenciam que, ao analisar o resultado olímpico dos jogos Rio-2016, observou-se uma relação moderada entre o PIB dos países e o seu desempenho olímpico. Neste sentido, há uma tendência de que os países com PIB mais elevado figurem, predominantemente, nas primeiras colocações do quadro de medalhas e, em contrapartida, os países com PIB reduzido, não figurem em posições de destaque.

Tais achados não se tratam de uma anormalidade. A literatura reporta como fatores diretamente relacionados com o desempenho olímpico o tamanho da população, o PIB, a vantagem de acolhimento - relacionado ao fato do indivíduo competir no seu país de origem - e a estrutura política dos países. Menciona-se ainda que, dentre estas variáveis, o PIB é a que está mais relacionada com o número de medalhas conquistadas por uma nação dentro das Olimpíadas (BERNARD; BUSSE, 2004; BIAN, 2005; LUIZ; FADAL, 2011).

Neste sentido, observa-se que o desempenho olímpico é influenciado por diversos fatores. Desta forma, mesmo que o PIB detenha posição de destaque na literatura, não é a única variável que influência o desempenho olímpico de uma nação. Isto justifica a obtenção de uma correlação moderada.

Quanto aos cálculos relacionados ao tamanho populacional, observam-se valores classificados como correlação moderada entre às variáveis número de medalhas de ouro e tamanho populacional $(\rho=0,487)$ e entre o número total de medalhas e o tamanho populacional $(\rho=0,451)$. Sendo assim, considera-se que o tamanho populacional se apresenta diretamente proporcional ao total de medalhas e o número de medalhas de ouro.

Sendo assim, ainda que o tamanho populacional apresente relação com o desempenho olímpico (SANTOS; COSTA; SILVA, 2012; BERNARD; BUSSE, 2004; BIAN, 2005; LUIZ; FADAL, 2011), chama a atenção o fato de que os valores de correlação que estiveram relacionados com o tamanho populacional (número de medalhas de ouro, $\rho=0,487$ e total de medalhas, $\rho=0,451$ ) foram inferiores em comparação aos valores de correlação relacionados com o PIB (número de medalhas de ouro, $\rho=0,633$ e total de medalhas, $\rho=0,528$ ).

Desta forma, os dados expostos por este estudo indicam que há indícios de que o PIB, em virtude do seu maior valor no teste de correlação, esteja mais relacionado com o desempenho olímpico do que o tamanho populacional, o que corrobora com o que foi descrito pela literatura.

Além disso, observou-se desempenho elevado de países não populosos, porém, com bom desenvolvimento econômico, como o Reino Unido, Holanda e a Coréia do Sul. Tal cenário coaduna com a perspectiva de Bernard e Busse (2004), que afirmam que o tamanho populacional não é o melhor indicador para explicar o número de 
medalhas olímpicas. Ademais, estes resultados convergem ao encontrado por Rathke e Woitek (2008), que indica a relação entre o número de medalhas e o tamanho populacional se acentua em nações economicamente mais desenvolvidas.

Outro ponto que merece destaque refere-se à premissa de que, segundo Bian (2005), países que tem em sua população um número elevado de praticantes de uma determinada modalidade aumentam, efetivamente, a probabilidade de o país conquistar uma medalha olímpica nesta. Exemplificando este contexto, cita-se o caso da Coréia do Sul, que apresenta, somado ao seu desenvolvimento econômico, a hegemonia no tiro com arco, aonde sempre é elevado o seu número de medalhas nos Jogos Olímpicos em tal modalidade.

Tal pressuposto está relacionado com o já mencionado fato de que o desempenho olímpico é influenciado por diversos fatores, e também justifica o fato da existência de correlações moderadas entre as variáveis arroladas na presente discussão.

Em relação à Paralimpíada, os dados igualmente apresentaram-se não normais com $\mathrm{p}<0,05$ no teste de normalidade Kolmogorov-Smirnov (número de medalhas de ouro, $\mathrm{p} \leq 0,001$; número total de medalhas, $\mathrm{p} \leq 0,001$; PIB $\mathrm{p} \leq 0,001$; tamanho populacional, $\mathrm{p} \leq 0,001)$. Assim, optou-se pelo cálculo de correlação de Spearman entre as referidas variáveis. A Tabela 2 apresenta os coeficientes da correlação, probabilidade associada (p-valor) e número de casos válidos $(\mathrm{N})$ :

Tabela 2 - Correlação de Spearman entre as variáveis paralímpicas de número de medalhas de ouro, total de medalhas, PIB e população

\begin{tabular}{|ll|r|r|r|r|}
\hline \multicolumn{7}{c}{ Correlações } \\
\hline
\end{tabular}

Nota: ** A correlação é significativa no nível 0,01 (bilateral).

Para $\mathrm{p}$-valor $=0,000$ utilizou-se arredondamento para $\mathrm{p}$-valor $=0,001$, seguindo recomendações.

Fonte: propostas na obra de DANCEY; REIDY (2006). 
Verifica-se que os valores retornados foram significativos com $\mathrm{p} \leq 0,001 \mathrm{em}$ todas as correlações investigadas pelo presente estudo, o que indica que há $99 \%$ de chance de, dos dados investigados estarem corretos. Não obstante, observa-se que todas as correlações retornadas se apresentaram positivas.

Verifica-se que há uma forte correlação entre as variáveis total de medalhas e número de medalhas de ouro $(\rho=0,857)$. Além disso, observa-se uma correlação moderada entre às variáveis PIB e número de ouro $(\rho=0,529)$, e PIB e total de medalhas $(\rho=0,566)$. Tal qual no que foi exposto no contexto olímpico, infere-se de forma moderada que, na medida em que o PIB aumenta, o número de medalhas de ouro e o número total de medalhas conquistadas também se eleva.

Quanto ao tamanho populacional, observam-se valores classificados como correlação moderada entre as variáveis número de medalhas de ouro e tamanho populacional $(\rho=0,566)$, e uma correlação fraca entre o número total de medalhas e o tamanho populacional $(\rho=0,396)$.

Os resultados, por meio do cálculo de correlação de Spearman em relação ao PIB, vão ao encontro dos dados apresentados por Santos, Costa e Silva (2012) e, naturalmente, se mostram bastante semelhantes ao cenário exposto no cálculo de correlação realizado com os dados das Olímpiadas.

Neste sentido, verifica-se que há uma tendência de que as variáveis elencadas pela literatura como determinantes para o desempenho olímpico, tais como o PIB, o tamanho populacional, a vantagem de acolhimento e a estrutura política dos países (BERNARD; BUSSE, 2004; BIAN, 2005; LUIZ; FADAL, 2011), também tendem a influenciar o desempenho paralímpico.

No entanto, da mesma forma como nas Olimpíadas, no caso dos Jogos Paralímpicos também ocorreu a existência de países sem PIB e população elevados que conquistaram um número considerável de medalhas, tais como a Ucrânia e a Polônia. Tal cenário indica, preliminarmente, que outros fatores, como a estrutura política e o investimento no paradesporto, podem também influenciar no desempenho paralímpico.

A comparação entre os valores de correlação das variáveis número de medalhas de ouro e número total de medalhas com o PIB ( $\rho=0,529$ e $\rho=0,566$, respectivamente) e tamanho populacional com o número total de medalhas $(\rho=0,396)$ permitem, preliminarmente, aventar que o potencial econômico, em comparação com o tamanho populacional, possui maior influência sobre o desempenho paralímpico no que tange ao total de medalhas.

Este fato pode ter ocorrido em virtude de que os países não disponibilizam um número exato de sua população com deficiência por meio de veículos confiáveis de 
comunicação. Além disso, o valor retornado pela correlação entre as variáveis número de medalhas de ouro e tamanho populacional $(\rho=0,556)$, encontrou-se próximo aos valores relacionados ao PIB (número de medalhas de ouro, $\rho=0,529$ e total de medalhas, $\rho=0,566$ ). Sendo assim, fica subentendido que mais testes são necessários para mapear e compreender este cenário.

Ao analisar o quadro de medalhas olímpico e paralímpico da soma bruta de medalhas, chama a atenção o desempenho de alguns países que conquistaram um elevado número de medalhas em uma competição, mas não replicam o desempenho na outra.

Entre os países que obtiveram desempenho expressivo na Paralimpíada, mas, não na Olimpíada, destacam-se a Ucrânia, $4^{\circ}$ pela soma bruta sendo $31^{\circ}$ na Olimpíada e $3^{\circ}$ na Paralimpíada, a Austrália, $5^{\circ}$ lugar pela soma bruta sendo $10^{\circ}$ na Olimpíada e $5^{\circ}$ na Paralimpíada, o Brasil, $7^{\circ}$ lugar pela soma bruta sendo $13^{\circ}$ na Olimpíada e $8^{\circ}$ na Paralimpíada e a Polônia, $16^{\circ}$ lugar pela soma bruta sendo $33^{\circ}$ na Olimpíada e $10^{\circ}$ na Paralimpíada.

Antagonicamente, entre os países que obtiveram um desempenho expressivo na Olimpíada, e não na Paralimpíada, destacam-se os Estados Unidos, $2^{\circ}$ pela soma bruta sendo $1^{\circ}$ nas Olimpíadas e $4^{\circ}$ nas Paralimpíada, a França, $8^{\circ}$ lugar pela soma bruta sendo $7^{\circ}$ na Olimpíada e $12^{\circ}$ na Paralimpíada, o Japão, $11^{\circ}$ lugar pela soma bruta sendo $6^{\circ}$ na Olimpíada e $64^{\circ}$ na Paralimpíada, a Coréia do Sul, $13^{\circ}$ lugar pela soma bruta sendo $8^{\circ}$ na Olimpíada e $20^{\circ}$ na Paralimpíada e, entre os países da América do Sul, a Colômbia, $25^{\circ}$ lugar pela soma bruta sendo $23^{\circ}$ na Olimpíada e $37^{\circ}$ na Paralimpíada e a Argentina, $50^{\circ}$ lugar pela soma bruta, sendo $27^{\circ}$ na Olimpíada e 54 na Paralimpíada.

Buscando elucidar o porquê de alguns países terem desempenhos Olímpico e Paralímpico distintos, elencou-se os casos dos Estados Unidos, com campanha melhor na Olimpíada, e do Brasil, com campanha melhor na Paralimpíada.

No caso dos Estados Unidos, tanto o esporte olímpico como o esporte paralímpico é gerido pela United States Olympic Committee (USOC). Logo, não há um comitê paralímpico autônomo. De acordo com Brittain (2010), há muitas questões que justificam um histórico desempenho paralímpico dos Estados Unidos inferior em relação ao seu desempenho olímpico, tais como o tratamento diferenciado que o USOC destina aos atletas paralímpicos, que recebem uma quantia expressivamente inferior de verbas de incentivo, bem como o crescimento da prática do esporte adaptado em outras nações, que culmina em consequente crescimento de desempenho em competições internacionais.

Tais fatores indicam uma menor atenção do país em relação ao esporte paralímpico, o que justifica seu desempenho inferior em relação aos Jogos Olímpicos. 
Já no caso do Brasil, o comitê olímpico é uma instituição distinta do comitê paralímpico nacional. Não obstante, de acordo com a lei $n^{0} 10.264$ de 16 de julho de 2001, conhecida como Lei Agnelo Piva, é previsto que 15\% do total da arrecadação de verba para o esporte seja destinado ao comitê paralímpico (BRASIL, 2001). Logo, o Brasil apresenta um maior percentual de investimento e uma gestão independente no esporte paralímpico, o que poderia justificar seu desempenho historicamente superior nos Jogos Paralímpicos.

Ao pensar em uma comparação entre os Jogos Olímpicos e Paralímpicos é importante ponderar que nas Olimpíadas há 306 disputas de medalhas. Tendo em vista que em algumas modalidades são distribuídas duas medalhas de bronze, há a distribuição de 53 medalhas de bronze a mais do que o número de medalhas de ouro e prata. As modalidades em que há disputa de duas medalhas de bronze são: boxe (13), judô (14), Taekwondo (8) e luta olímpica (18). Por sua vez, nas Paralimpíadas há 528 disputas de medalhas, ocorrendo também à distribuição de 13 medalhas de bronze adicionais na modalidade de judô. Em ambas as competições, como já retratado, há divergências entre o total de medalhas disputadas e o total de medalhas distribuídas, em virtude dos empates.

Tendo em vista a divergência no número de medalhas em disputas, a partir da aplicação do fator de correção descrito na seção de procedimentos metodológicos do presente estudo, foi gerado o quadro de medalhas e classificação exposto no Quadro 2.

Quadro 2 - Quadro de medalhas veiculado pela mídia na Olimpíada e Paralimpíada Rio2016 e soma com pesos do número de medalhas em ambas as competições e suas respectivas classificações

\begin{tabular}{|c|c|c|c|c|c|c|c|c|c|c|c|c|c|c|c|}
\hline \multirow{2}{*}{$\begin{array}{l}\text { COLOCAÇAO } \\
\text { PELA SOMA } \\
\text { COM PESOS }\end{array}$} & \multirow{2}{*}{$\begin{array}{l}\text { COLOCACACAO } \\
\text { (OLIMP.) }\end{array}$} & \multirow{2}{*}{$\begin{array}{l}\text { COLOCACAO } \\
\text { (PARALIMP.) }\end{array}$} & \multirow{2}{*}{ PAIS } & \multicolumn{4}{|c|}{ OLIMPIADAS } & \multicolumn{4}{|c|}{ PARALIMPIADAS } & \multicolumn{4}{|c|}{ SOMA COM PESOS } \\
\hline & & & & OURO & PRATA & BRONZE & TOTAL & OURO & PRATA & BRONZE & TOTAL & OURO & PRATA & BRONZE & TOTAL \\
\hline $01^{\circ}$ & $03^{\circ}$ & $01^{\circ}$ & China & 26 & 18 & 26 & 70 & 107 & 81 & 51 & 239 & 151,86 & 112,06 & 90,18 & 354,10 \\
\hline $02^{\circ}$ & $01^{\circ}$ & $04^{\circ}$ & $\begin{array}{l}\text { Estados } \\
\text { Unidos }\end{array}$ & 46 & 37 & 38 & 121 & 40 & 44 & 31 & 115 & 119,37 & 107,84 & 88.26 & 315,48 \\
\hline $03^{\circ}$ & $02^{\circ}$ & $02^{\circ}$ & Reino Unido & 27 & 23 & 17 & 67 & 64 & 39 & 44 & 147 & 110.59 & 78,69 & 69,62 & 258,89 \\
\hline $04^{\circ}$ & $05^{\circ}$ & $06^{\circ}$ & Alemanha & 17 & 10 & 15 & 42 & 18 & 25 & 14 & 57 & 47,33 & 42,25 & 36,60 & 126,19 \\
\hline $05^{\circ}$ & $31^{\circ}$ & $03^{\circ}$ & Ucrânia & 2 & 5 & 4 & 11 & 41 & 37 & 39 & 117 & 44,45 & 45,63 & 45,03 & 135,11 \\
\hline $06^{\circ}$ & $10^{\circ}$ & $05^{\circ}$ & Austrália & 8 & 11 & 10 & 29 & 22 & 30 & 29 & 81 & 35,80 & 48,98 & 44,07 & 128,85 \\
\hline $07^{\circ}$ & $04^{\circ}$ & $\cdot$ & Rússia & 19 & 18 & 19 & 56 & & & & & 32,78 & 31,06 & 28,63 & 92,48 \\
\hline $08^{\circ}$ & $11^{\circ}$ & $07^{\circ}$ & Holanda & 8 & 7 & 4 & 19 & 17 & 19 & 26 & 62 & 30,80 & 31,08 & 32,03 & 93,91 \\
\hline $09^{\circ}$ & $07^{\circ}$ & $12^{\circ}$ & França & 10 & 18 & 14 & 42 & 9 & 5 & 14 & 28 & 26,25 & 36,06 & 35,10 & 97,41 \\
\hline $10^{\circ}$ & $13^{\circ}$ & $08^{\circ}$ & Brasil & 7 & 6 & 6 & 19 & 14 & 29 & 29 & 72 & 26,08 & 39,35 & 38,04 & 103,47 \\
\hline $11^{\circ}$ & $09^{\circ}$ & $09^{\circ}$ & Itália & 8 & 12 & 8 & 28 & 10 & 14 & 15 & 39 & 23,80 & 34,71 & 27,06 & 85,57 \\
\hline $12^{\circ}$ & $08^{\circ}$ & $20^{\circ}$ & Coreia do Sul & 9 & 3 & 9 & 21 & 7 & 11 & 17 & 35 & 22,53 & 16,18 & 30.56 & 69.27 \\
\hline $14^{\circ}$ & $06^{\circ}$ & $64^{\circ}$ & Japảo & 12 & 8 & 21 & 41 & & 10 & 14 & 24 & 20,71 & 23,80 & 45,65 & 90,16 \\
\hline $22^{\circ}$ & $33^{\circ}$ & $10^{\circ}$ & Polónia & 2 & 3 & 6 & 11 & 9 & 18 & 12 & 39 & 12,45 & 23,18 & 21,04 & 56,67 \\
\hline $32^{\circ}$ & $23^{\circ}$ & $37^{\circ}$ & Colómbia & 3 & 2 & 3 & 8 & 2 & 5 & 10 & 17 & 7,18 & 8,45 & 14,52 & 30,15 \\
\hline $37^{\circ}$ & $27^{\circ}$ & $54^{\circ}$ & Argentina & 3 & 1 & & 4 & 1 & 1 & 3 & 5 & 6,18 & 2,73 & 3,00 & 11,90 \\
\hline $80^{\circ}$ & $65^{\circ}$ & $65^{\circ}$ & Venezuela & & 1 & 2 & 3 & & 3 & 3 & 6 & 0,00 & 4,73 & 6,01 & 10,74 \\
\hline $94^{\circ}$ & - & $76^{\circ}$ & $\cdot$ & & & & & & & 1 & 1 & 0,00 & 0,00 & 1,00 & 1,00 \\
\hline
\end{tabular}

Nota: *Empate entre cinco países: Arábia Saudita, Cabo Verde, Moçambique, Paquistão e Sri Lanka.

Verifica-se que não houve alteração nas três primeiras colocações em relação à classificação pela soma bruta de medalhas, mantendo a China, Estados Unidos e Reino 
Unido em primeiro, segundo e terceiro lugar respectivamente. Ainda que os Estados Unidos apresentem um desempenho inferior na Paralimpíada em relação à Olimpíada, a análise pela soma com pesos reforça que os países mantêm considerável número de conquista de medalhas em ambas as competições.

Não obstante ao contexto supracitado, nota-se que em ambos os quadros apresentados por este estudo, os países que se classificaram nas dez primeiras colocações no quadro de medalhas gerado a partir da soma bruta, mantiveram-se entre os dez primeiros na classificação gerada a partir da soma com pesos. Além disso, a partir da quarta colocação, é perceptível algumas alterações de posicionamento dos países. A Alemanha assume o quarto lugar ao ultrapassar a Ucrânia $\left(5^{\circ}\right)$, a Rússia passa de décimo para sétimo, o Brasil cai de sétimo para décimo e a Holanda sobe para a oitava colocação, ultrapassando a França $\left(9^{\circ}\right)$. Em relação aos países da América do Sul, a ordem dos países não se alterou, mantendo a Colômbia $\left(32^{\circ}\right)$ a frente da Argentina $\left(37^{\circ}\right)$ e Venezuela $\left(80^{\circ}\right)$.

À luz do cenário exposto, chama a atenção a queda da Ucrânia para quinto, a queda do Brasil para décimo e a ascensão da Rússia ao sétimo lugar. Em relação à Ucrânia e ao Brasil, a mencionada queda na classificação evidencia que sua classificação a partir da soma bruta de medalhas é reflexo de seu desempenho paralímpico, em ambos os casos superior ao seu desempenho olímpico. Neste sentido, quando se equipara o peso das medalhas, as melhores colocações tendem a permanecer com os países que obtiveram desempenhos mais equilibrados nas duas competições, o que fez com que Ucrânia e Brasil decaíssem algumas posições.

\section{CONSIDERAÇÕES FINAIS}

A análise dos quadros de medalhas divulgados pela mídia nos Jogos Olímpicos e Paralímpicos reforça, tanto pela soma bruta de medalhas quanto no método de classificação por peso das medalhas, que a China, os Estados Unidos e o Reino Unido conquistaram um elevado número de medalhas em ambas as competições, o que reforça o elevado potencial olímpico/paralímpico destes países.

Ademais, verifica-se que alguns países apresentam um desempenho expressivo em apenas uma das competições. Entre os que se destacam nos Jogos Paralímpicos e não repetem o desempenho nos Jogos Olímpicos destaca-se a Ucrânia, a Austrália, o Brasil e a Polônia. Antagonicamente, entre os países que se destacam em maior proporção nos Jogos Olímpicos em relação à Paralimpíada destacam-se os Estados Unidos, a França, o Japão, a Coréia do Sul e, entre os países da América do Sul, a Colômbia e a Argentina. 
A literatura retorna como justificativa a este panorama, a diferença de investimento dos países para com os comitês organizadores do esporte olímpico e paralímpico, bem como a autonomia que estes têm para fomentar o esporte ao qual estão responsáveis por gerir. Ainda assim, sugere-se a necessidade de novos estudos para a detecção de variáveis intervenientes que venham a influenciar neste processo.

Não obstante, os cálculos de correlação de Spearman referentes aos resultados dos Jogos Olímpicos e Paralímpicos em relação ao tamanho populacional e ao PIB indicam, no que tange aos Jogos Olímpicos, que o tamanho populacional e o PIB estão moderadamente relacionados com o número total de medalhas e com o número de medalhas de ouro. Quanto aos Jogos Paralímpicos, nota-se uma relação moderada entre o tamanho populacional e o número de medalhas de ouro, uma relação fraca entre o tamanho populacional e o total de medalhas, e uma relação moderada entre o PIB e o número total de medalhas e número de medalhas de ouro.

Estes resultados coadunam com o que fora reportado por Santos, Costa e Silva (2012), e indicam que nos Jogos Olímpicos Rio-2016 o PIB esteve mais relacionado com o desempenho olímpico do que o tamanho populacional, em virtude dos valores de correlação se apresentarem superiores. No caso dos Jogos Paralímpicos, há a necessidade de que mais estudos sejam complementarmente realizados, visto que não foi possível utilizar os dados da população com deficiência de cada país, o que representa uma limitação do presente estudo.

Adicionalmente, sugere-se como estudo futuro, um aprofundamento nas investigações acerca do hiato existente no desempenho entre ambas as competições por parte de alguns países, tal qual uma análise temporal que transcenda o estudo exclusivo de uma edição dos jogos, de forma a buscar explicações do porquê algumas nações apresentarem resultados expressivos em uma edição, não o replique em edições subsequentes.

\section{REFERÊNCIAS}

ARAÚJO, Allyson Carvalho. De Atenas a Sidney: registros audiovisuais dos jogos olímpicos. Recorde, Rio de Janeiro, v. 6, n. 1, p. 1-7, jul. 2013.

BRASIL. Lei $\mathrm{n}^{\mathrm{o}} 10.264$, de 16 de julho de 2001. Acrescenta inciso e parágrafos ao art. 56 da Lei $n^{\circ} 9.615$, de 24 de março de 1998, que institui normas gerais sobre desporto. Diário Oficial da República Federativa do Brasil, Brasília DF, 16 jul. 2001. Disponível em: <http://www.planalto.gov.br/ccivil_03/leis/LEIS_2001/L10264.htm>. Acesso em: 10 out. 2016. 
BERNARD, Andrew; BUSSE, Meghan. Who wins the olympic games: economic resources and medal totals. Review of Economics and Statistics, Cambridge, v. 86, n. 1, p. 413-417, mar. 2004.

BIAN, Xun. Predicting olympic medal counts: the effects of economic development on olympic performance. The Park Place Economist, Illinois, v.13, p. 37-44, 2005.

BRITTAIN, Ian. The paralympic games explained. New York: Taylor \& Francis, 2010.

COLLI, Eduardo. Universo olímpico. São Paulo: Codéx, 2004.

COMITÊ OLÍMPICO INTERANCIONAL (COI). Summer sports: 2016. Disponível em: <https://www.olympic.org/sports $>$. Acesso em: 23 set. 2016.

CONSELHO FEDERAL DE EDUCAÇÃO FÍSICA (CONFEF). Cada medalha conta. 2012. Disponível em: <http://www.confef.org.br/extra/revistaef/show.asp?id=4050>. Acesso em: 23 ago 2016.

COSTA, Alberto Martins; SOUSA, Sônia Bertoni. Educação física e esporte adaptado: história, avanços e retrocessos em relação aos princípios da integração/inclusão e perspectivas para o século XXI. Revista Brasileira de Ciências do Esporte, Curitiba, v. 25 , n. 3, p. 27-42, maio 2004.

DANCEY, Christine; REIDY, John. Estatística sem matemática para psicológica. 3. ed. Porto Alegre: Artmed, 2006.

INTERNATIONAL MONETARY FUND (FMI). Subdued demand diminished prospects. $2016 . \quad$ Disponível em: $<$ http://www.imf.org/external/pubs/ft/weo/2016/update/01/> Acesso em: 22 ago. 2016.

INTERNATIONAL PARALYMPIC COMMITTEE (IPC). Modalidade. 2016. Disponível em: < http://www.cpb.org.br/modalidades>. Acesso em: 23 set. 2016.

LUIZ, John; FADAL, Riyas. An economic analysis of sports performance in Africa. Wits Business School, v. 38, n. 10, p. 869-883, jan. 2011.

MARQUES, Renato Francisco Rodrigues. et al. Esporte olímpico e paralímpico: coincidências, divergências, e especificidades numa perspectiva contemporânea. Revista Brasileira de Educação Física e Esporte, São Paulo, v. 23, n. 4, p. 365-377, out./dez. 2009.

ORGANIZAÇÃO DAS NAÇÕES UNIDAS (ONU). World population prospects, the 2015 revision. 2016. Disponível em: <https://esa.un.org/unpd/wpp/>. Acesso em: 22 ago. 2016. 
ORGANIZAÇÃO DAS NAÇÕES UNIDAS. National accounts main aggregates database. 2015. Disponível em: <http://unstats.un.org/unsd/snaama/dnllist.asp > Acesso em: 22 ago. 2016.

SANTOS, Silvestre Cirilo; COSTA, Lamartine Pereira; SILVA, Carlos Henrique Vituoso. Rio 2016 e o plano Brasil medalhas: seremos uma potência olímpica? Podium: sports, leisure and tourism review, São Paulo, v. 1, n. 1, p. 66-87, jan./jun. 2012.

RATHKE, Alexander; WOITEK, Ulrich. Economics and the summer olympics: and efficiency Analysis. Journal of Sports Economics, v. 9, n. 5, p. 520-537, dec. 2008.

THE WORLD BANK. GDP Ranking. 2016. Disponível em: $<$ http://data.worldbank.org/data-catalog/GDP-ranking-table>. Acesso em: 22 ago. 2016. 